\title{
On Domain-Specific Conceptualization and Measurement of Grit in L2 Learning
}

\author{
Yasser Teimouri, Boğaziçi University \\ iD https://orcid.org/0000-0002-2661-9835
}

yasser.teimouri@boun.edu.tr

\section{Ekaterina Sudina, Northern Arizona University}

iD https://orcid.org/0000-0002-1925-5658

ekaterina.sudina@nau.edu

Luke Plonsky, Northern Arizona University

iD https://orcid.org/0000-0002-5791-1839

lukeplonsky@gmail.com

\begin{abstract}
As a personality trait, second language (L2) grit-a combination of perseverance and passion for L2 learning-has recently been proposed as a meaningful predictor of learners' motivational behavior and L2 achievement. The results of a growing body of empirical studies carried out in various L2 contexts have substantiated the power of L2 grit in predicting L2 success. In this paper, we contend that grit and its potential effects on L2 outcomes should be conceptualized and measured in a domain-specific fashion. We argue that a domain-specific measure of grit enhances its predictive and construct validity and better captures its differential effects in various domains and across languages. We then briefly review the findings of existing grit research in L2 contexts with respect to their domain-general versus domain-specific conceptualization of grit. Finally, we conclude the paper by discussing several issues raised against domain-general grit and discuss their potential relevance to domain-specific grit research in the context of L2 learning.
\end{abstract}

Keywords: domain-general grit, domain-specific grit, personality, L2 learning, L2 achievement 


\section{INTRODUCTION}

Language learning is a goal-directed process, and language mastery is highly dependent on L2 learners' sustained effort and passion over a long period of time (e.g., Dörnyei, 2020; Dörnyei \& Henry, in press). As such, the study of grit - the combination of perseverance and passion for long-term goals 1 - and its effects on learner achievement and motivation appears immediately relevant in SLA (Sudina \& Plonsky, 2021a; Teimouri et al., 2020). Indeed, the results of a growing body of empirical studies carried out in various L2 contexts have substantiated the power of L2 grit in predicting L2 success (e.g., Alamer, 2021; Chen et al., 2021; Elahi Shirvan et al., 2021; Sudina, Brown, et al., 2021; Sudina \& Plonsky, 2021a, 2021b; Teimouri et al., 2020; Teimouri et al., under review; Wei et al., 2020).

In this paper, we argue that grit and its potential effects on L2 outcomes should be conceptualized and measured in a domain-specific fashion. We then briefly review the findings of existing grit research in L2 contexts with respect to their domain-general versus domain-specific conceptualization of grit. Finally, we conclude the paper by discussing several issues raised against domain-general grit (e.g., Credé et al., 2017; Credé, 2018) and discuss their potential relevance to domain-specific grit research in the context of L2 learning.

\section{ARGUMENTS FOR A DOMAIN-SPECIFIC MEASREMENT OF GRIT IN SLA}

Teimouri et al. (2020) called for a domain-specific approach toward the role of grit (and other personality traits) in L2 learning. The need to measure grit as a domain-specific construct has also been echoed by scholars in mainstream social and educational psychology (e.g., Duckworth \& Quinn, 2009; Eskreis-Winkler et al., 2014). A few studies have even taken the initiative to empirically explore the domain-specific versus the domain-general aspects of grit in various contexts, such as sports (Cormier et al., 2019), education (Schmidt et al., 2017), and L2 learning (Sudina \& Plonsky, 2021b; Teimouri et al., 2020). The findings of these studies have consistently shown that (a) students' levels of domain-specific grit are higher than their domaingeneral grit and that (b) domain-specific grit is a better predictor of achievement (e.g., GPAs) than domain-general grit. In the following sections, we offer four arguments in favor of measuring grit in a domain-specific manner in L2 learning contexts.

\section{A Domain-Specific Measure of Grit Improves its Predictive Validity}

In a general sense, domain-general personality measures do not assess nuanced variations of personality traits with respect to outcomes in any individual domain. This is because "to a certain extent people are the same regardless of context, and to a certain extent they also are different depending on the context" (Pervin \& John, 2001, p. 290). As noted by Dörnyei and Ryan (2015), these contextual variations of personality have significant implications, both in theory and practice, for SLA research. For instance, the inconclusive findings regarding the part personality plays in L2 learning (Chen et al., 2021), especially when compared to the robust findings of other learner-internal factors like L2 motivation and anxiety (for a review, see Dörnyei \& Ryan, 2015), can be arguably attributed to the applications of domain-general personality measures in SLA research (Teimouri et al., 2020). As argued by Teimouri et al. (2020), a domain-specific measure of personality will strengthen findings of personality research in SLA because learners' personality traits and language achievement will be both measured at the same language-domain-specific levels. Therefore, we might expect that a domain-specific measure of grit will increase its psychometric power in predicting L2 outcomes because of the local consistency of measurements. And, in fact, a small but growing body of studies examining the relationships between domain-general and domainspecific grit and L2 achievement has found this to be true. For example, whereas Teimouri et al. (2020) found grit and L2 speaking scores to be correlated at $r=.18, \mathrm{~L} 2$ grit and L2 speaking scores were correlated at $r=.30$.

\section{A Domain-Specific Measure of Grit Better Captures its Differential Effects in Specific Domains}

Not only do personality traits show variations across contexts, but they also exert differential effects on the individuals' behaviors and success outcomes. For instance, 
the personality trait of conscientiousness may be deemed essential for scientists, whereas it may bear slight significance for artists (see Baer, 2016). Likewise, the openness to experience may be vital for artists yet less meaningful for mathematicians (see Feist, 1998). Intriguingly, a high level of grit in certain situations may even be harmful if it prevents the individual from seeking help despite recurring failures, or if it pushes the individual to persist in solving challenging problems when investing time and energy on more solvable ones is more valuable and efficient (Credé et al., 2017). Being gritty may not be as helpful in some domains as in L2 learning, wherein success depends on fulfilling the very challenging long-term goal of mastering a second or foreign language. Therefore, a domain-specific measure of grit allows us to zoom in on its unique effects on L2 learning outcomes.

\section{A Domain-Specific Assessment of Grit Enhances its Construct Validity.}

As noted by Duckworth and associates, grit is defined as a composite of perseverance and passion for long-term goals (see Duckworth et al., 2007, 2021). The long-term goal component of grit has been argued to be one of its key features distinguishing it from other related traits such as conscientiousness (Duckworth et al., 2007). Given the goaldirected nature of grit, it would be plausible to witness individuals who exhibit differential levels of perseverance and passion in various domains depending on their adopted goals. As suggested by Duckworth and Quinn (2009), "It is possible that an individual shows tremendous grit in her or his professional life but none at all in her or his personal relationships. Similarly, it may be that an individual sees oneself as gritty with respect to a serious hobby but not with respect to one's career" (p. 173). In the L2 learning context, for instance, research has shown that foreign language learners' grit level for pursuing their L2 goals is significantly higher than their general grit level (e.g., Sudina \& Plonsky, 2021b; Teimouri et al., 2020). Therefore, a domain-specific measure of grit better maps onto its conceptual definition, thereby enhancing its construct validity.

\section{A Domain-Specific Measure of Grit Better Captures its Cross-Language Differences.}

L2 learning is different from learning other subjects due to the political, historical, social, psychological, educational, and cultural features underlying each target language and its community. As such, multilinguals may think, feel, and act differently across their acquired languages in various domains. Research has already identified language effects on values, self-concept, moral judgment, emotional expressions, and cognition (e.g., Costa et al., 2014; Dewaele, 2016; Oyserman \& Lee, 2008; Ross et al., 2002). For instance, multilinguals make more utilitarian decisions in their additional (vs. native) languages when encountering moral dilemmas (e.g., Should you sacrifice one man to save five? see Costa et al., 2014, for more) or react differently to emotional and emotion-laden words across languages (e.g., I love you; see Dewaele, 2008, 2016, for more). A few studies have also demonstrated cross-language differences in personality traits within multilinguals (e.g., Chen \& Bond, 2010; Hall, 1996; Ramirez-Esparza et al., 2006). For instance, when Spanish bilinguals assessed their personality traits concerning their second language (i.e., English), they identified themselves as more extroverted, agreeable, and conscientious, and less neurotic (Ramirez-Esparza et al., 2006). These cross-language differences in personality can be attributed to cultural background, cultural accommodation, social role, gender, language proficiency, and language dominance of multilinguals among others (see Chen \& Bond, 2010, for more). A domain-general measure of personality traits, however, assumes certain stability of traits across domains and ignores language as a contextual factor that may lead to shifts of personality traits. Thus, a domain-specific measure of grit better accounts for its cross-language differences.

\section{PRELIMINARY EVIDENCE FOR A DOMAIN- SPECIFIC MEASURE OF GRIT}

Research on grit in the context of L2 learning is gaining momentum (e.g., Alamer, 2021; Changlek \& Palanukulwong, 2015; Khajavy et al., 2020; Kramer et al., 2017; Lake, 2013; Robins, 2019; Wei et al., 2019; Yamashita, 2018). In fact, interest in the role of grit in L2 learning likely surpasses any other personality trait in SLA research in recent years. Overall, these studies have highlighted the positive role of grit in L2 learners' 
motivational behavior, emotional experiences, and L2 achievement.

Grit researchers have used a domain-general or a domainspecific measure of grit in their studies, or both. Those studies that have used a domain-general measure of grit have yielded less consistent findings regarding the path between grit and L2 learning outcomes. For instance, whereas some studies have found domain-general grit to be positively but weakly related to L2 achievement (e.g., Robin, 2019; Wei et al., 2019), others detected virtually no relationship between the two (e.g., Khajavy et al. 2020; Yamashita, 2018). In contrast, studies that have adopted a domain-specific measure of grit have revealed predominantly positive and substantial relations between L2 grit and L2 achievement and proficiency (e.g., Alamer, 2021; Sudina \& Plonsky, 2021a, 2021b; Sudina, Brown, et al., 2021; Teimouri et al., 2020, under review). Critically, as noted above, when both domain-general and domainspecific measures of grit have been used, the findings have identified domain-specific grit as having a much stronger relationship with L2 achievement than domain-general grit (e.g., Sudina \& Plonsky, 2021b; Teimouri et al., 2020). Moreover, domain-specific grit has even been found to predict L2 achievement as powerfully as language aptitude (Teimouri et al., under review).

\section{ON THE CRITICISMS OF DOMAIN-GENERAL GRIT AND THEIR RELEVANCE IN L2 LEARNING}

Despite the exponential growth of grit research in various domains, this construct has not escaped criticism (e.g., Credé, 2018; Credé et al., 2017; Hofer, 2010; Muenks et al., 2017; Rimfeld et al., 2016). In the following paragraphs, we discuss the three main issues that have been raised against domain-general grit and address their relevance and significance to domain-specific grit research in the context of L2 learning.

\section{Grit as a Higher-Order Personality Trait}

How is grit related to other similar personality traits, such as conscientiousness and its sub-components (e.g., selfcontrol)? Duckworth et al. (2007) argued that grit is distinct from conscientiousness in that although both traits emphasize hardworking-ness, grit emphasizes it specifically in relation to one's long-term goal; moreover, the passion sub-component of grit toward a long-term goal is another factor distinguishing grit from conscientiousness. However, Credé et al.'s (2017) meta-analysis showed a strong correlation between grit and conscientiousness ( $r$ $=.84$ ), leading the authors to argue that grit and conscientiousness are probably the same constructs with different labels - the so-called jangle fallacy. Nonetheless, it should be noted that, as we argued before, the long-term goal component of grit is an important feature that theoretically distinguishes it from conscientiousness (and other similar traits). Yet, none of the items in the domaingeneral grit scales encompass a long-term goal. Moreover, the content of the scales used to measure domain-general grit has been problematized (e.g., Credé et al., 2017). Therefore, any claims regarding the relation between domain-general grit and conscientiousnes (and other factors) should be interpreted with caution because of the limitations of the scales used to measure grit.

In the L2 learning domain, however, the research that has adopted a domain-specific approach toward conceptualization and measurement of grit has not shown any meaningful relationships between grit and conscientiousness (and its sub-components), suggesting that the jangle fallacy likely does not hold. For instance, in Teimouri et al. (2020), domain-specific grit was found to be unrelated to conscientiousness; likewise, Sudina and Plonsky (2021a) detected a weak correlation between domain-specific grit and the industriousness facet of conscientiousness. These preliminary findings do not substantiate the claims that grit is overlapping with conscientiousness (e.g., Credé et al., 2017) and its facets such as industriousness (Schmidt et al., 2018) - at least not in the L2 learning domain. It is thus premature to discuss the jangle fallacy in the SLA context due to the rarity of research regarding (a) the role of conscientiousness (and its sub-components) in L2 learning (see Chen et al., 2021) and (b) its correlation with L2 grit.

\section{Grit as a Predictor of Success and Performance}

Another criticism against domain-general grit concerns its power in predicting success outcomes in various domains. According to Duckworth and colleagues (Duckworth et al., 2007; Duckworth \& Quinn, 2009), grit is as important as talent in determining students' success. The results of 
various studies in educational contexts, for instance, have found gritty students to have higher course grades (e.g., Duckworth et al., 2007; Strayhorn, 2014), higher educational aspirations (e.g., Duckworth et al., 2007), and higher rates of education (Eskreis-Winkler et al., 2014). Nevertheless, Credé et al.'s (2017) meta-analysis of grit studies revealed only a weak, positive correlation between domain-general grit and academic performance $(r=.18)$. Similarly, Lam and Zhou (2021) reported a weak, positive correlation $(r=.19)$ between domain-general grit and academic achievement in their meta-analysis of grit research in educational contexts. In addition, these two meta-analyses identified the perseverance sub-component of domain-general grit as a better correlate of achievement than its passion sub-component, leading the authors to recommend against combining perseverance and passion sub-components of grit while examining their effects on achievement. $^{2}$

In SLA research, on the other hand, the research examining the links between domain-specific grit and L2 achievement has shown promising results. Although the L2 studies that used a domain-general measure of grit have produced somewhat inconsistent findings (Khajavy et al., 2020; Robins, 2019; Wei et al., 2019; Yamashita, 2018), the studies that have used domain-specific grit scales have predominantly found grit as a significant, positive factor in L2 learning and teaching (e.g., Sudina \& Plonsky, 2021a, 2021b; Sudina, Brown, et al., 2021; Sudina, Vernon, et al., 2021; Teimouri et al., 2020). Notably, the effects of domain-general grit versus domain-specific grit on L2 learning have also been scrutinized, and the findings have identified domain-specific grit as having much stronger effects on L2 learning than domain-general grit. Considering the relationship between L2 achievement and the sub-components of L2 grit, although perseverance was generally found to be more strongly related to L2 achievement than passion (e.g., Teimouri et al., 2020), a reverse pattern was observed in Sudina and Plonsky (2021a), in which passion was found to be a superior predictor of L2 achievement than perseverance. All in all, in contrast to the findings of Credé et al.'s (2017) and Lam and Zhou's (2021) meta-analyses, SLA research has shown a more robust relationship between L2 grit and achievement, substantiating our arguments regarding the importance of grit in the L2 learning context and, in particular, the need for adopting a domain-specific approach toward this construct.

\section{Grit as a Compound of Perseverance and Passion}

Another criticism against the domain-general grit concerns its measurement using existing scales. Originally, Duckworth and her associates developed a 12-item scale to measure grit (Duckworth et al., 2007). Later on, Duckworth and Quinn (2009) created a shorter version of the scale (8 items) and examined its higher-order construct validity by testing a hierarchical structure with two first-order factors for perseverance and passion. However, such a statistical method is not conclusive because any hierarchical model with two first-order factors and a nonhierarchical model with two correlated first-order factors are indistinguishable (Credé et al., 2017; Credé, 2018). Instead, Credé et al. (2017) recommended examining the strength of the correlation between the two sub-components of grit as a more useful approach in determining the validity of grit as a higherorder construct. In other words, a relatively high correlation between perseverance and passion can be construed as good evidence supporting grit as a higher-order construct.

In a recent paper, Duckworth and her associates acknowledged their error of interpretation while validating their grit scales (Duckworth et al., 2021). Nonetheless, noting that the absence of evidence is not evidence of absence, they highlighted the results of a meta-analysis by Guo et al. (2019), in which the average correlation between passion and perseverance across 39 studies was .43. This finding, according to Duckworth et al. (2021), cannot be taken as evidence for or against a higher-order structure of grit. Considering the factor structure of grit, Duckworth et al. (2021) argued, "Since the construct of grit refers to a compound of passion and perseverance for long-term goals, the operationalization of grit should refer to both tendencies" (p. 574). In their re-analysis of the grit data by Duckworth and Quinn (2009), Duckworth et al. (2021) examined various possible specifications for modeling covariance among grit items and identified high correlations $(r \geq .91)$ among different specifications of grit: average of grit subscales, single grit factor, hierarchical grit factor, bifactor grit factor (where "subscales" refer to observed variables and "factors" refer to factor scores from latent variables). Moreover, the various specifications of grit revealed very similar predictive validity. 
In SLA research, grit studies have used both domaingeneral and domain-specific grit scales. In Teimouri et al. (2020), we developed and validated an L2 grit scale to be used specifically in the L2 learning domain. The validity and reliability of the scale were further examined in several studies conducted with language learners in Canada, China, Iran, Japan, Russia, South Korea, and the US (e.g., Elahi Shirvan et al., 2021; Sudina \& Plonsky, 2021a, 2021b; Sudina, Brown, et al., 2021; Teimouri et al., 2020; Wei et al., 2020). Factorial and reliability analyses have substantiated the two-component structure of the L2 grit scale as well as its internal consistency. The reliability of this L2 grit scale was found to be slightly higher than Duckworth et al.'s (2007) domain-general grit (e.g., Sudina \& Plonsky, 2021b; Teimouri et al., 2020). The concurrent validity of the L2 grit scale was achieved (a) when the students' self-reported grit scores strongly correlated with their teachers' perception of their perseverance and passion over the semester (Teimouri et al., 2020) and (b) when language learning grit subscale scores for students' second and third languages were correlated with domain-general grit subscale scores (see Sudina \& Plonsky, 2021b). The predictive and postdictive validity of L2 grit was also achieved when it turned out to be a much stronger predictor of the students' motivational behaviors and language achievement than the domain-general grit scale (e.g., Sudina \& Plonsky, 2021b; Teimouri et al., 2020). Moreover, the perseverance and passion sub-components of the L2 grit have been found to be correlated with medium-to-large effect sizes in foreign language contexts $(r \mathrm{~s}=.58-.68$ in Sudina, Brown, et al., 2021; Sudina \& Plonsky, 2021a, 2021b; see Plonsky \& Oswald, 2014 for the interpretation of the magnitude of effect sizes in L2 research), suggesting that "a higher order construct is plausible" (Credé et al., 2017, p. 493; see also Credé, 2018). ${ }^{3}$

\footnotetext{
${ }^{1}$ Throughout the paper, we used the terms perseverance and passion to refer to perseverance of effort and consistency of interest, respectively.
}

\section{CONCLUSION}

Grit research is expanding steadily in SLA research, indicating a renewed interest in personality research after a longstanding lull in this area. In this position paper, we championed an evidence-based approach toward the study of grit in the context of L2 learning. Although individual differences research in SLA has been traditionally informed and inspired by sister disciplines such as social and educational psychology, the research findings obtained in these neighboring domains should be further scrutinized in the L2 field to better grasp the roles of learner-internal factors - and grit in particular - in L2 learning. For instance, the two meta-analyses conducted on the role of domaingeneral grit (Credé et al., 2017; Lam \& Zhou, 2021) have rarely included studies conducted in the L2 learning context. Thus, it would be inappropriate to assume that such findings will generalize to L2 learning. We would never assume that the relationship between motivation and (general) academic achievement, for example, would equal that of L2 motivation and L2 achievement, would we? Given the unique nature of L2 learning processes and experiences, we maintain that a domain-specific measure of grit offers a more precise tool for assessing subtle variations of grit in the L2 context and its influence on L2 learners' behaviors and language achievement. As such, we encourage SLA researchers to conceptualize and measure grit (and other personality traits) in a domain-specific fashion. If a researcher is interested in examining the influence of a personality trait like grit on learning a given target language, the student's personality traits should be assessed with respect to the task of language learning, at the very least or, ideally, in relation to that particular language in order to achieve the most meaningful results. We further encourage SLA researchers to measure L2 grit in accordance with its theoretical conceptualization. Finally, we welcome any endeavors and innovations directed at developing and validating new measures of grit, its sub-components of perseverance and passion, as well as its relationships with other related constructs (see Sudina \& Plonsky, 2021a).

\footnotetext{
2 Duckworth et al. (2021), however, emphasized that although they were not opposed to examining the two facets separately, they were more in favor of "using the sum of both subscales" when measuring grit (p. 574).
} 
${ }^{3}$ In fact, this was exactly the reason why Sudina, Brown, et al. (2021) explored the possibility of a higher-order CFA - the results of EFA revealed that two L2 grit factors in the EFL sample correlated at .60, which is a large effect size.

\section{REFERENCES}

Alamer, A. (2021). Grit and language learning: Construct validation of grit and its relation to later vocabulary knowledge. Educational Psychology, 41(3), 544-562. https://doi.org/10.1080/01443410.2020.1867076

Baer, J. (2015). Domain specificity of creativity. Academic Press.

Changlek, A., \& Palanukulwong, T. (2015). Motivation and grit: Predictors of language learning achievement. Veridian E-Journal, 8(4), 23-38.

Chen, S. X., \& Bond, M. H. (2010). Two languages, two personalities? Examining language effects on the expression of personality in a bilingual context. Personality and Social Psychology Bulletin, 36(11), 1514-1528. https://doi.org/10.1177/0146167210385360

Chen, X., Lake, J., \& Padilla, A. M. (2021). Grit and motivation for learning English among Japanese university students. System, 96. https://doi.org/10.1016/j.system.2020.102411

Cormier, D. L., Dunn, J. G., \& Dunn, J. C. (2019). Examining the domain specificity of grit. Personality and Individual Differences, 139, 349-354.

https://doi.org/10.1016/j.paid.2018.11.026

Costa, A., Foucart, A., Hayakawa, S., Aparici, M., Apesteguia, J., Heafner, J., \& Keysar, B. (2014). Your morals depend on language. PloS One, 9(4), 1-7. https://doi.org/10.1371/journal.pone.0094842

Credé, M. (2018). What shall we do about grit? A critical review of what we know and what we don't know. Educational Researcher, 47, 606-611. https://doi.org/10.3102/0013189X18801322

Credé, M., Tynan, M. C., \& Harms, P. D. (2017). Much ado about grit: A meta-analytic synthesis of the grit literature. Journal of Personality and Social

Psychology, 113, 492-511.

https://doi.org/10.1037/pspp0000102

Dewaele, J. M. (2010). Emotions in multiple languages. Springer.

Dewaele, J. M. (2008). The emotional weight of I love you in multilinguals' languages. Journal of Pragmatics, 40(10), 1753-1780. https://doi.org/10.1016/j.pragma.2008.03.002

Dörnyei, Z. (2020). Innovations and challenges in language learning motivation. Routledge.

Dörnyei, Z., \& Henry, A. (in press). Accounting for longterm motivation and sustained motivated learning: Motivational currents, self-concordant vision, and persistence in language learning. In A.J. Elliot (Ed.), Advances in motivation science, Vol. 9. Academic Press.

Dörnyei, Z., \& Ryan, S. (2015). The psychology of the language learner revisited. Routledge.

Duckworth, A. L., Peterson, C., Matthews, M. D., \& Kelly, D. R. (2007). Grit: Perseverance and passion for long term goals. Journal of Personality and Social Psychology, 92, 1087-1101. https://doi.org/10.1037/0022-3514.92.6.1087

Duckworth, A. L., \& Quinn, P. D. (2009). Development and validation of the short grit scale (Grit-S). Journal of Personality Assessment, 91, 166-174. https://doi.org/10.1080/00223890802634290

Duckworth, A. L., Quinn, P. D., \& Tsukayama, E. (2021). Revisiting the factor structure of grit: A commentary on Duckworth and Quinn (2009). Journal of Personality Assessment, 103(5), 573575. https://doi.org/10.1080/00223891.2021.1942022

Elahi Shirvan, M., Taherian, T., Shahnama, M., \& Yazdanmehr, E. (2021). A longitudinal study of 
foreign language enjoyment and L2 grit: A latent growth curve modeling. Frontiers in Psychology, 12. https://doi.org/10.3389/fpsyg.2021.720326

Eskreis-Winkler, L., Duckworth, A. L., Shulman, E. P., \& Beal, S. (2014). The grit effect: Predicting retention in the military, the workplace, school and marriage. Frontiers in Psychology, 5, 36. https://doi.org/10.3389/fpsyg.2014.00036

Feist, G. J. (1998). A meta-analysis of personality in scientific and artistic creativity. Personality and Social Psychology Review, 2(4), 290-309. https://doi.org/10.1207/s15327957pspr0204_5

Griffin, M. L., McDermott, K. A., McHugh, R. K., Fitzmaurice, G. M., \& Weiss, R. D. (2016). Grit in patients with substance use disorders. The American Journal on Addictions, 25(8), 652-658. https://doi.org/10.1111/ajad.12460

Guo, J., Tang, X., \& Xu, K. M. (2019). Capturing the multiplicative effect of perseverance and passion: Measurement issues of combining two grit facets. Proceedings of the National Academy of Sciences of the United States of America, 116(10), 39383940. https://doi.org/10.1073/pnas.1820125116

Hull, P. V. (1996). Bilingualism: Some personality and cultural issues. In D. I. Slobin, J. Gerhardt, A. Kyratzis, \& J. Guo (Eds.), Social interaction, social context, and language: Essays in honor of Susan Ervin-Tripp (pp. 419-434). Erlbaum.

Hofer, M. (2010). Adolescents' development of individual interests: A product of multiple goal regulation? Educational Psychologist, 45, 149-166. https://doi.org/10.1080/00461520.2010.49346 9

Lam, K. K. L., \& Zhou, M. (2021). Grit and academic achievement: A comparative cross-cultural metaanalysis. Journal of Educational Psychology. Advance online publication. https://doi.org/10.1037/edu0000699

Khajavy, G. H., MacIntyre, P., \& Barabadi, E. (2018). Role of the emotions and classroom environment in willingness to communicate: Applying doubly latent multilevel analysis in second language acquisition research. Studies in Second Language
Acquisition, 40(3), 605-624.

https://doi.org/10.1017/s0272263117000304

Kramer, B., McLean, S., \& Shepherd Martin, E. S. (2017). Student grittiness: A pilot study investigating scholarly persistence in EFL classrooms. Osaka Jokaguin Junior College Kiyo, 47, 25-41.

Lake, J. (2013). Positive L2 self: Linking positive psychology with L2 motivation. In T. M. Apple, D. Da Silva, \& T. Fellner (Eds.), Language learning motivation in Japan (pp. 71-225). Multilingual Matters.

Muenks, K., Wigfield, A., Yang, J. S., \& O’Neal, C. R. (2017). How true is grit? Assessing its relations to high school and college students' personality characteristics, self-regulation, engagement, and achievement. Journal of Educational Psychology, 109, 599-620. https://doi.org/10.1037/edu0000153

Oyserman, D., \& Lee, S. S. W. (2007). Priming "culture": Culture as situated cognition. In S. Kitayama \& D. Cohen (Eds.), Handbook of cultural psychology (pp. 255-279). Guilford.

Pervin, L. A., \& John, O. P. (2001). Personality: Theory and research (8th ed.). Wiley.

Plonsky, L., \& Oswald, F. L. (2014). How big is "big"? Interpreting effect sizes in L2 research. Language Learning, 64, 878-912. https://doi.org/10.1111/lang.12079

Ramirez-Esparza, N., Gosling, S. D., Benet-Martinez, V., Potter, J. P., \& Pennebaker, J. W. (2006). Do bilinguals have two personalities? A special case of cultural frame switching. Journal of Research in Personality, 40, 99-120. https://doi.org/10.1016/j.jrp.2004.09.001

Rimfeld, K., Kovas, Y., Dale, P. S., \& Plomin, R. (2016). True grit and genetics: Predicting academic achievement from personality. Journal of Personality and Social Psychology, 111, 780-789. https://doi.org/10.1037/pspp0000089

Robins, S. (2019). Academic achievement and retention among ESL learners: A study of grit in an online context [Unpublished doctoral dissertation]. University of West Georgia. 
Ross, M., Xun, W. Q. E., \& Wilson, A. E. (2002). Language and the bicultural self. Personality and Social Psychology Bulletin, 28, 1040-1050. https://doi.org/10.1177/01461672022811003

Schmidt, F. T., Fleckenstein, J., Retelsdorf, J., EskreisWinkler, L., \& Möller, J. (2019). Measuring grit: A German validation and a domain-specific approach to grit. European Journal of Psychological Assessment, 35, 436-447. https://doi.org/10.1027/1015-5759/a000407

Sudina, E., Brown, J., Datzman, B., Oki, Y., Song, K., Cavanaugh, R., Thiruchelvam, B., \& Plonsky, L. (2021). Language-specific grit: Exploring psychometric properties, predictive validity, and differences across contexts. Innovation in Language Learning and Teaching, 15, 334-351. https://doi.org/10.1080/17501229.2020.1802468

Sudina, E., \& Plonsky, L. (2021a). Academic perseverance in foreign language learning: An investigation of language-specific grit and its conceptual correlates. The Modern Language Journal. Advance online publication. https://doi.org/10.1111/modl.12738
Sudina, E., \& Plonsky, L. (2021b). Language learning grit, achievement, and anxiety among L2 and L3 learners in Russia. International Journal of Applied Linguistics, 172, 161-198. https://doi.org/10.1075/itl.20001.sud

Sudina, E., Vernon, T., Foster, H., del Villano, H., Hernandez, S., Beck, D., \& Plonsky, L. (2021). Development and initial validation of the L2teacher grit scale. TESOL Quarterly, 55, 156-184. https://doi.org/10.1002/tesq.581

Teimouri, Y., Plonsky, L., \& Tabandeh, F. (2020). L2 grit: Passion and perseverance for second-language learning. Language Teaching Research. Advance online publication. https://doi.org/10.1177/1362168820921895

Teimouri, Y., Tabandeh, F., \& Tahmouresi, S. (under review). The hare and the tortoise: The race on the course of L2 learning.

Wei, H., Gao, K., \& Wang, W. (2019). Understanding the relationship between grit and foreign language performance among middle school students: The roles of foreign language enjoyment and classroom environment. Frontiers in Psychology, 10. https://doi.org/10.3389/fpsyg.2019.01508 